\title{
POPULISMO, CRISIS DE REPRESENTACIÓN Y DEMOCRACIA
}

\author{
Juan Santiago YLARRI \\ Profesor de Elementos de Derecho Constitucional \\ Universidad de Buenos Aires (Argentina) \\ Máster en Derecho Constitucional, \\ Centro de Estudios Políticos y Constitucionales \\ Doctorando, Universidad de Buenos Aires \\ juan@ylarri.com.ar
}

1. El concepto de populismo es difícil de determinar, así como el hecho de clasificar a un gobierno como populista o no. El populismo, siendo un fenómeno que se dio en América Latina en los años treinta y cuarenta del siglo $\mathrm{Xx}$, se ha presentado con nuevos matices a finales del siglo pasado en muchos países latinoamericanos, e incluso parece haber cruzado las fronteras de aquel continente para echar raíces en Europa. El presente trabajo tiene por objeto trazar algunos rasgos que caracterizan al fenómeno del populismo y ver en qué medida se han dado sus notas en los gobiernos del presidente Menem y de Néstor Kirchner y Cristina Fernández en Argentina. Se prestará particular atención a las consecuencias jurídicas que derivan de este fenómeno.

En este contexto, en primer lugar, se estudiarán las diversas formas en que puede encararse un estudio sobre el populismo y se explicará la relación entre este fenómeno y las crisis de representación, y sus consecuencias para la democracia. Luego se hará una breve referencia al populismo histórico de Perón y se analizará en qué medida pueden considerarse como populistas los gobiernos de Carlos Menem, por un lado, y de Néstor Kirchner y Cristina Fernández, por el otro.

2. Si existe una cuestión en común entre todas las investigaciones sobre el populismo es que es un concepto muy difícil de enmarcar y definir, siendo que con el mencionado término se designan realidades distintas ${ }^{1}$. Incluso la palabra populismo tiene en el lenguaje corriente una connotación negativa,

${ }^{1}$ Excedería el propósito de este trabajo analizar todas y cada una de las teorías acerca del populismo. Se habla de teorías formalistas, teoría estructural-funcionalista o clásica, teorías evasivas, la escuela desarrollista, el populismo como alianza policlasista y la teoría pos- 
al estar estrechamente asociado con términos como demagogia y prodigalidad económica, que indican irresponsabilidad económica o política² ${ }^{2}$.

Al momento de determinar el concepto del populismo, Laclau señala que hay que preguntarse si el populismo es un movimiento, una ideología o una práctica política. Sostiene que el populismo es una categoría ontológica y no óntica, es decir, que su significado no debe hallarse en ningún contenido político o ideológico que entraría en las prácticas de cualquier grupo específico, sino en un determinado modo de articulación de esos contenidos sociales, políticos o ideológicos, cualesquiera ellos sean ${ }^{3}$.

Desde una aproximación formal, el autor citado señala que no hay que preguntarse si un movimiento es o no populista, sino hasta qué punto aquél es populista. En este sentido refiere que ningún movimiento político va a estar exento de populismo, ya que ninguno va a dejar de interpelar hasta cierto punto al «pueblo» contra un enemigo mediante la construcción de una frontera social. Es por ello que las referencias populistas van a mostrarse de una manera particularmente clara en momentos de transición política, cuando el futuro de la comunidad está en juego. En este marco, señala que populismo significa cuestionar el orden constitucional mediante la construcción de un pueblo como agente histórico, es decir, un agente que es un «otro» en relación con el orden vigente ${ }^{4}$.

Por otro lado, a fin de hacer un acercamiento al concepto de populismo, Panizza señala que su enfoque puede ser abordado en tres grandes categorías: la de «generalizaciones empíricas», que intenta extraer una serie de características definitorias positivas que podría ofrecer un grupo distintivo de atributos para caracterizar el fenómeno; «explicaciones historicistas», que consiste en vincular el populismo con un determinado periodo histórico, formación social, proceso histórico o conjunto de circunstancias históricas, y el enfoque de las «interpretaciones sintomáticas», que incorpora algunos de los rasgos que caracterizan al populismo según los enfoques empírico e historicista, pero justifica su inclusión en función del núcleo analítico del concepto sobre la base de la constitución del pueblo como un actor político ${ }^{5}$.

marxista. Véase al respecto C. Moscoso Perea, El populismo en América Latina, Madrid, Centro de Estudios Constitucionales, 1990.

${ }^{2}$ F. PANIZZA, «El populismo como espejo de la democracia», en F. PANIZZA (coord.), El populismo como espejo de la democracia, México, Fondo de Cultura Económica, 2009, p. 9.

3 E. Laclau, «Populismo: ¿qué nos dice el nombre?», en F. Panizza (coord.), El populismo como espejo de la democracia, México, Fondo de Cultura Económica, 2009, pp. 52 y 53, e íD., La razón populista, México, Fondo de Cultura Económica, 2005.

${ }^{4}$ E. Laclau, «Populismo...», op. cit.

${ }^{5}$ F. PANIZZA, «El populismo...», op. cit., pp. 11-13. 
Desde el punto de vista de las «generalizaciones empíricas» se han destacado diversos rasgos relevantes que permitirían caracterizar al populismo en sus diversas experiencias. En primer lugar, la presencia de un discurso antipolítico en el cual el rechazo a la política aparece como uno de los ejes de la convocatoria que cae en un terreno fértil en aquellas sociedades donde los partidos y el ejercicio de la actividad política es mal evaluada por la población. En segundo lugar, se afirma que el populismo tiene un claro estilo mediático de comunicación política, estableciendo una especie de diálogo directo entre la conducción y la base. En tercer lugar, hay una fuerte voluntad de movilización, en tanto importantes sectores de la población son convocados para dar respaldo social al discurso y acción populista. En cuarto lugar, se distingue la retórica nacionalista, siendo que la apelación al sentimiento nacionalista sería como uno de los vehículos emocionales que la conducción populista establece con la población. En quinto lugar, se hace referencia a la conducción personalizada, en tanto el populismo tiene siempre un caudillo como conductor y su carisma es uno de los elementos constitutivos de la conformación de la convocatoria populista. En sexto lugar, estaría la desconfianza en las instituciones, con lo cual éstas quedan descolocadas como canales de mediación. Se dice que el populismo puede ganar adeptos donde las instituciones han entrado en desprestigio ${ }^{6}$.

Teniendo en cuenta las características del populismo, también se lo ha definido, en un sentido amplio y descriptivo, como un movimiento político (o la fase de un movimiento más amplio) que se basa, para su eficacia, en amplias movilizaciones de masas a partir de una retórica de contenido fundamentalmente emocional y autoafirmativo, centrada en torno a la idea de un «pueblo» como depositario de las virtudes sociales de justicia y moralidad, y vinculada a un líder, habitualmente carismático, cuya honestidad y fuerza de voluntad garantiza el cumplimiento de los deseos populares. Se señala que el rasgo característico del populismo es su contenido moral, tanto por lo que al pueblo se refiere como por lo que atañe al líder ${ }^{7}$.

${ }^{6}$ A. Benavente Urbina y J. A. Cirinio, La democracia defraudada. Populismo revolucionario en América Latina, 1. a ed., Buenos Aires, Grito Sagrado, 2005, pp. 37-39.

7 S. TORres Ballesteros, «El populismo. Un concepto escurridizo», en J. Álvarez Junco (coord.), Populismo, caudillaje y discurso demagógico, 1. ${ }^{a}$ ed., Madrid, Centro de Investigaciones Sociológicas, 1987, p. 171.

En efecto, la retórica está muy presente en los populismos. Respecto a la argumentación retórica véase M. AtienzA, El derecho como argumentación, Barcelona, Ariel, 2006, pp. 250-263. 
Habiendo explicado brevemente el enfoque de las generalizaciones empíricas, cabe referirse también al punto de vista de las «explicaciones historicistas». En este enfoque se caracteriza al populismo como un fenómeno histórico, es decir, el populismo de los años treinta y cuarenta del siglo pasado, como el de Getulio Vargas en Brasil y el de Juan Domingo Perón en Argentina ${ }^{8}$.

Por último, el «enfoque sintomático» entiende al populismo como un discurso anti statu quo que simplifica el espacio político mediante la división simbólica de la sociedad entre el «pueblo» y su «otro». Éstas son construcciones políticas constituidas simbólicamente mediante la relación de antagonismo y no categorías sociológicas. Se afirma que una dimensión anti statu quo es esencial al populismo, ya que la constitución plena de las identidades populares necesita la derrota política del «otro», el cual es percibido como opresor o explotador del pueblo y, por tanto, como el que impide su presencia plena. El «otro» en oposición al «pueblo» puede ser presentado en términos políticos o económicos, significando «los políticos», «la oligarquía» o cualquier otro grupo que impida al pueblo lograr la plenitud ${ }^{9}$. Sobre este aspecto se volverá más adelante.

También se ha señalado que una de las características del populismo es la presencia de un líder fuerte, generalmente carismático ${ }^{10}$. Así, en relación con la retórica populista se afirma que el hábil uso del lenguaje, su conexión con el imaginario popular, las estrategias y juegos de palabras que los populistas desde siempre han intentado articular, es parte de un escenario que está estrechamente ligado e identificado con el fenómeno en Latinoamérica. Es a través de las estructuras argumentativas y las fórmulas retóricas, en definitiva, de las palabras, cuando actores políticos como los populistas pueden desplegar su capacidad estratégica para transmitir a sus audiencias diversas significaciones y representaciones de la realidad ${ }^{11}$. Se habla también de la delegación del pueblo en un portavoz, indicándose que los populismos en América Latina emplean el lenguaje y los elementos simbólicos como el vínculo y la representación de un pacto con los sectores populares. Estos últimos, a su vez, depositan su confianza, y, por tanto,

${ }^{8}$ L. Paramio, «La izquierda y el populismo», en P. Pérez Herrero (coord.), La «izquierda» en América Latina, Madrid, Pablo Iglesias, 2006, pp. 26 y ss.

${ }^{9}$ F. PANIZZA, «El populismo...», op. cit., pp. 13-14.

${ }^{10}$ Sobre el liderazgo carismático véase R. M. ARRANZ, «El liderazgo carismático en el contexto del estudio del liderazgo», en J. Álvarez Junco (coord.), Populismo, caudillaje y discurso demagógico, 1. ed., Madrid, Centro de Investigaciones Sociológicas, 1987, pp. 73-99.

${ }^{11}$ C. Elórtegui Gómez, Populismo y comunicación: la política del malestar en el contex-

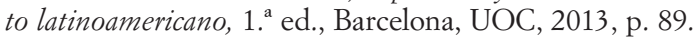


sus apoyos políticos manifestados en votos, cuando son partícipes y testigos de lo simbólico ${ }^{12}$.

Habiendo efectuado una referencia a las distintas formas de abordar el concepto de populismo, cabe ahora hacer mención a la estrecha relación entre aquel fenómeno y la crisis de representación ${ }^{13}$. En efecto, se ha definido la crisis de representación como una crisis de adaptación del sistema de partidos a una nueva realidad económica y social, en una fase en la que las reglas del juego han cambiado y en la que los políticos no aciertan a responder a las demandas sociales bajo estas nuevas reglas de juego. Indica que los actores políticos no encuentran estrategias adecuadas para mantener identidades con las que los electores se puedan identificar, quienes se sienten frustrados con las consecuencias de su voto. El problema se suscita cuando los partidos acumulan una sucesión de fracasos o no aparecen como alternativas creíbles, por lo que el descrédito puede extenderse al sistema de partidos y a los partidos como «clase» ${ }^{14}$.

Los populismos han surgido en contextos de crecimiento de la pobreza y por la frustración de muchos sectores de no ver representados sus intereses. De esta forma, en muchos países los sistemas de partidos establecidos no han generado ofertas políticas creíbles que permitieran a estos sectores sentirse representados y, como consecuencia de ello, ha ido creciendo el escepticismo hacia las instituciones políticas en su conjunto ${ }^{15}$.

Sin embargo, cabe aclarar que la aparición de liderazgos populistas no exige necesariamente un colapso previo del sistema de partidos. La condición fundamental es la existencia de una crisis de representación donde una parte importante de la sociedad siente que ninguno de los partidos existentes representa sus intereses. Al respecto se ha dicho que «la con-

${ }^{12}$ Ibid., pp. 104 y 106.

13 En cuanto al concepto de representación y la historia del pensamiento político que han tratado dicho concepto véase el clásico trabajo de H. PITKIN, The Concept of Representation, Berkeley, University of California Press, 1967. Asimismo, sobre la crisis de la representación véase I. GUTIÉRREZ (coord.), La democracia indignada. Tensiones entre voluntad popular y representación política, Granada, Comares, 2014.

${ }^{14}$ L. Paramio, «La izquierda...», op. cit., pp. 26 y ss. Sobre el tema véase también L. Paramio, «Crisis de gobernabilidad y populismo», en L. Paramio y M. Revilla (coords.), Una nueva agenda de reformas políticas en América Latina, Madrid, Fundación Carolina, 2006, p. 17.

En relación con la desconfianza ciudadana a los partidos véase L. PARAMIO, «Cambios sociales y desconfianza política: el problema de la agregación de preferencias», Revista Española de Ciencia Política, núm. 1 (1999), pp. 81-95.

15 L. Paramio, «Giro a la izquierda y regreso del populismo», Nueva Sociedad, vol. 205 (2006), p. 66. 
solidación de un liderazgo populista contribuye a profundizar la crisis de los partidos preexistentes, ya que su discurso fomenta el descrédito de éstos y a menudo sus políticas están dirigidas a socavar los mecanismos de funcionamiento de la representación, erosionando sus bases sociales y recortando su papel en las instituciones. En último término, el ataque a la supuesta "oligarquía política" conduce casi inevitablemente a un ataque a las propias instituciones políticas —más allá de los partidos-y al intento de crear una nueva institucionalidad a la medida del régimen populista, lo que puede tener efectos negativos muy duraderos para la vida política democrática, más allá del propio ciclo populista» ${ }^{16}$.

En la misma línea, Laclau afirma que en la experiencia clásica de una ruptura populista o revolucionaria - que generalmente es resultado de los tipos de crisis de representación que Gramsci denominó «crisis orgánicas»- un sistema institucional se vuelve cada vez menos capaz de absorber diferencialmente las demandas sociales, y esto conduce a una brecha interna dentro de la sociedad y a la construcción de dos cadenas de equivalencias antagonistas ${ }^{17}$.

Se ha dicho que estas crisis de representación que han dado lugar al surgimiento de los populismos podrían tener lugar bajo tres circunstancias distintas, que coinciden con los tres gobiernos que presentan notas de populismo en Argentina: el surgimiento del peronismo, el populismo neoliberal de la última década del siglo xx con el presidente Menem y el populismo de las presidencias de Néstor Kirchner y Cristina Fernández. En efecto, se ha señalado que los fracasos en la representación son característicos de épocas de agitación política, cultural, social y económica, así como también es en estas épocas cuando relaciones de representación y subordinación antes relativamente estables se vuelven inciertas y no alineadas, y, por tanto, abiertas a nuevas formas de identificación. La primera circunstancia que favorece el surgimiento de la política populista estaría constituida por los cambios a nivel de la economía, la cultura y la sociedad, como los procesos de urbanización y modernización económica, y los cambios en el equilibrio demográfico entre clases sociales y entre grupos regionales y étnicos. Se pone como ejemplo que en la década de 1930, en Argentina, una nueva clase trabajadora compuesta por migrantes de las provincias rurales hacia las nuevas industrias en ciudades como Buenos Aires y Rosario se convirtió en la base social del peronismo en la década de 1940. La

${ }^{16}$ Ibid., p. 68.

17 E. LaClau, «Populismo...», op. cit., p. 67. 
segunda circunstancia es una ruptura del orden social y la pérdida de confianza en la capacidad del sistema político para restaurarlo. Las crisis económicas que se manifiestan en fenómenos como la hiperinflación son típicas de estas situaciones, como se dio en el advenimiento al gobierno del presidente Menem. Una tercera situación es el agotamiento de las tradiciones políticas y el desprestigio de los partidos políticos por las acusaciones de corrupción y la falta de rendición de cuentas de sus actos, por lo que el populismo toma la forma de «la política de la antipolítica», ya que los políticos y los partidos se convierten en el «otro» del pueblo, que podríamos relacionarlo con el advenimiento de los gobiernos kirchneristas ${ }^{18}$.

Es en este punto donde hay que detenerse y analizar las consecuencias del populismo para la democracia ${ }^{19}$. Como señala Paramio, toda vez que el populismo constituye un fenómeno político, su crítica debe partir de las consecuencias que tiene para la democracia y sus instituciones antes de analizar su política económica e independientemente de que ésta encaje o no en el estereotipo del populismo económico. Como se verá más adelante, la política económica del populismo clásico es muy distinta de la de los gobiernos populistas que aplicaron políticas neoliberales ${ }^{20}$. De esta forma, su análisis debe efectuarse con total independencia de su balance económico o de las consecuencias de su política social. En esta línea, el autor mencionado ha dicho que los nuevos populismos conducen al desmantelamiento o la perversión de las instituciones democráticas y, muy en particular, de las que cumplen la función de contrapesar o controlar al poder ejecutivo. $\mathrm{El}$ autor mencionado considera que la herencia política del populismo es de una enorme gravedad, toda vez que después del populismo no sólo es preciso recuperar las instituciones democráticas, sino también la confianza de los ciudadanos en ellas. Además, el problema de la crisis de representación se agrava si el propio sistema de partidos ha resultado arrasado por el

${ }^{18}$ F. PANIZZA, «El populismo...», op. cit., pp. 24-26.

19 Por otro lado, ARDiTi habla de tres modalidades del populismo en relación con la política democrática moderna: «como modo de representación», «como síntoma» y «como reverso». Afirma que no puede determinarse conceptualmente cuándo este fenómeno se puede convertir en un reverso de la democracia, sino que es una cuestión de criterio político. En este sentido sostiene que el populismo puede permanecer dentro de los límites de la democracia, pero también puede llegar al punto en el que ambos entran en conflicto y pueden incluso llegar a tomar caminos separados. Cfr. B. ARDITI, «El populismo como periferia interna de la política democrática», en F. PANIZZA (coord.), El populismo como espejo de la democracia, México, Fondo de Cultura Económica, 2009, pp. 97-132.

${ }^{20}$ Sin embargo, hay quienes han descrito de una determinada forma el modelo económico de los populismos. Véase R. Dornbusch y E. EDwards (eds.), The Macroeconomics of Populism in Latin America, Chicago, University of Chicago Press, 1991. 
gobierno populista, siendo más dificultoso reconstruir identidades partidarias capaces de estabilizar la representación política ${ }^{21}$.

En esta línea se ha señalado que para caracterizar a los populismos se puede acudir a los términos que evocan las nociones clásicas de «elective despotism» de Thomas Jefferson, «despotismo democrático» de Alexis de Tocqeville o «democracia plebiscitaria» de Max Weber ${ }^{22}$, y más recientemente se ha hecho referencia al «autoritarismo electoral» ${ }^{23}$. En efecto, como bien señala Amartya Sen, existe una visión más antigua y más formal de la democracia que carga el acento en las elecciones y los votos, en lugar de la más amplia perspectiva del gobierno por discusión. Por el contrario, una comprensión amplia de la democracia está caracterizada por la participación política, el diálogo y la interacción pública ${ }^{24}$. El autor citado destaca también que si bien los votos tienen una función para la expresión y la efectividad del proceso de razonamiento público, no es lo único que importa, pues se trata tan sólo de una parte - aunque muy relevante- de la forma en que la razón pura opera en una sociedad democrática. En esta línea sostiene que la efectividad de los votos depende de manera decisiva de lo que se juega en las urnas, como la libertad de expresión, el acceso a la información y el derecho a disentir. «Votar a secas puede ser en sí mismo completamente inadecuado, como lo muestran con elocuencia las insólitas victorias electorales de tiranías en ejercicio o regímenes autoritarios del pasado y del presente, por ejemplo, en Corea del Norte» ${ }^{25}$.

Otra de las cuestiones de los populismos señalada como lesiva para la democracia es el «discurso populista». Paramio señala que este discurso «denuncia a la elite política anterior y al conjunto de los partidos políticos tradicionales como traidores a los intereses populares, para presentar a los nuevos gobernantes como verdaderos representantes de esos intereses. Y por ello pide el máximo respaldo social para evitar que la oposición bloquee la acción del gobierno desde las instituciones democráticas» ${ }^{26}$.

Se ha dicho que este discurso político se caracterizaría por descalificar a una oligarquía - de la que son parte sustancial los políticos de partido- dirigiéndose a los individuos como miembros de un colectivo, el pue-

${ }^{21}$ L. Paramio, «Giro a la izquierda...», op. cit., pp. 68-69.

${ }^{22}$ Cfr. J. Lanzaro (ed.), Presidencialismo y parlamentarismo. América Latina y Europa meridional, Madrid, Centro de Estudios Políticos y Constitucionales, 2012, p. 45.

23 A. SCHEDlen, Electoral Authoritarianism, Boulder, Lynne Rienner, 2006.

${ }^{24}$ A. SEn, La idea de la justicia, Buenos Aires, Taurus, 2009, pp. 354 y 356.

${ }^{25}$ Ibid., p. 357.

${ }^{26}$ L. Paramio, «Giro a la izquierda...», op. cit., pp. 64-65. 
blo, víctima de la oligarquía. El populismo, entendido de esta forma, es el discurso de un líder que asume la representación del pueblo fuera de los partidos preexistentes y frente a ellos. Todas las organizaciones políticas y sociales que se presenten como un obstáculo a su liderazgo o no lo acepten estarán condenadas a ser englobadas dentro de la oligarquía, debiendo ser, por tanto, reemplazadas por otras realmente «populares». Por tanto, se considera que es evidente que una crisis de representación, definida de ese modo, es el contexto más favorable para la aparición de líderes populistas. A su vez, se resalta que la aparición y continuidad de un líder populista constituye una amenaza a las instituciones políticas. «Es obvio que la consolidación de un líder populista contribuye a profundizar la crisis de los partidos preexistentes, ya que su discurso fomenta su descredito y a menudo sus políticas estarán dirigidas a socavar los mecanismos de funcionamiento de la representación, erosionando sus bases sociales y recortando su papel en las instituciones. En este último término, el ataque a la oligarquía política conduce casi inevitablemente a un ataque a las propias instituciones políticas - mas allá de los partidos- y el intento de crear una nueva institucionalidad a la medida del régimen populista, lo que puede tener efectos negativos muy duraderos para la vida política democrática, más allá del propio ciclo populista» ${ }^{27}$.

En esta línea, Weyland caracteriza al populismo como una estrategia política en donde un líder personal apela a una heterogénea masa de seguidores que se sienten excluidos y que están disponibles para la movilización. El líder llega a sus seguidores de una manera directa, casi personal, que pasa por encima de las organizaciones intermedias establecidas, especialmente los partidos, y si revive un antiguo partido populista sigue siendo un vehículo con un bajo nivel de institucionalización ${ }^{28}$.

De esta forma, como bien se ha señalado, el populismo, incluso si se somete a las reglas de juego de la democracia, no es un proyecto democrático. Divide a la sociedad a través de su distinción maniquea entre sectores populares y oligárquicos, basa su discurso en la confrontación y no pretende crear ciudadanos, sino seguidores ${ }^{29}$.

3. Antes de referirnos al caso de los gobiernos de Menem, Kirchner y Fernández, y determinar si se trata de nuevos populismos, cabe señalar que al gobierno de Juan Domingo Perón se lo ha considerado como populis-

27 L. Paramio, «La izquierda...», op. cit., pp. 26 y ss.

${ }^{28}$ K. Weyland, «Neoliberal Populism in Latin America and Eastern Europe», Comparative Politics, vol. 31, núm. 4 (1999), p. 381.

${ }^{29}$ L. Paramio, «Giro a la izquierda...», op. cit., pp. 62-74. 
ta. En efecto, las experiencias de los gobiernos de Perón en Argentina y de Getulio Vargas en Brasil son uno de los ejemplos clásicos del populismo latinoamericano, denominándose a este populismo como «histórico».

Se ha dicho que la crisis de representación de los años veinte y el cambio de reglas de juego económicas en los treinta fueron el contexto en el que surgieron y se consolidaron estos regímenes populistas. Esos regímenes expandieron fuertemente la administración y los poderes del Estado, desarrollaron políticas sociales redistributivas y fomentaron una industrialización, sustitutiva de las importaciones y de tipo proteccionista, que expandió el empleo urbano y creó las condiciones para la inclusión social de las capas trabajadoras. Gracias a esas políticas sociales y económicas los regímenes populistas se crearon una base social propia, movilizándolos como electores. La crisis de representación quedó resuelta, por decirlo así, con la aparición de partidos populistas de masas ${ }^{30}$. En efecto, en aquellos años existían amplios grupos sociales que se sentían excluidos económicamente y no encontraban una vía para que sus necesidades fueran atendidas por los gobiernos ${ }^{31}$. Se lo ha definido también como un populismo urbano e industrial clásico ${ }^{32}$.

Uno de los elementos indispensables de este populismo lo constituía la figura carismática de Perón, a la cual habría que agregar la de su mujer, Eva Duarte, prematuramente fallecida en $1952^{33}$.

En la última década del siglo xx también se han calificado ciertos gobiernos latinoamericanos como populistas, como podría tratarse del caso del gobierno de Carlos Menem en Argentina y, sin lugar a dudas, del de Alberto Fujimori en Perú. Hacia finales de los años ochenta - llamada la «década pérdida»-, por la gravedad de la crisis de la deuda se había extendido la idea de que era imprescindible cambiar el modelo económico, en la medida en que el modelo proteccionista centrado en la intervención y el gasto público parecía crecientemente inviable. De esta forma, Menem y Fujimori trataron de realizar una agenda económica neoliberal, combinándola con políticas sociales clientelares para obtener a la vez el apoyo del

${ }^{30}$ L. PARAmIO, «La izquierda...», op. cit., pp. 26 y ss.

${ }^{31}$ L. Paramio, «Giro a la izquierda...», op. cit., p. 66.

32 B. ArdiTI, «El populismo...», op. cit., p. 99.

33 A. Benavente Urbina y J. A. Cirinio, La democracia defraudada..., op. cit., p. 69. Asimismo, los autores señalan que si bien formalmente el sistema siguió siendo democrático, puesto que el Congreso Nacional siguió funcionando, el peronismo ya en 1947 tenía mayoría absoluta, lo cual posibilitó la posterior reforma constitucional por la cual se cercenaron las atribuciones del Parlamento, y sostienen que la oposición parlamentaria, que en sí era débil, pasó a ser un elemento decorativo. 
empresariado, las clases medias y las clases populares ${ }^{34}$. Así, se ha afirmado que hubo una compatibilidad inesperada entre el populismo económico y el liberalismo económico en la América Latina de los años noventa ${ }^{35}$.

De todas formas cabe aclarar que se encuentra en debate si el gobierno de Menem puede ser considerado como populista. En este sentido, Paramio indica que en el gobierno de Menem se dieron bastantes rasgos del discurso y la forma de gobernar populistas. Señala que si bien se podría objetar que Menem venía del partido tradicional y se limitaba a volver a los orígenes, la forma en que se planteó su candidatura, en desafío a la dirección renovadora del Partido Justicialista, y su propio origen periférico dentro de éste permitían ver en su emergencia un desafío al sistema de partidos ${ }^{36}$. Como se dijo anteriormente, el populismo puede darse con independencia de un sistema económico determinado ${ }^{37}$. Las políticas privatizadoras y liberalizadoras de la economía se alejaban mucho del populismo histórico, pero su legitimidad social se asentó en haber puesto fin a la hiperinflación ${ }^{38}$, que en el caso argentino había llegado, por ejemplo, en el mes de junio de 1989, a un 114 por 100.

Lanzaro no considera al menemismo como un auténtico populismo ${ }^{39}$. Otros afirman que sí lo fue, como Mayorga ${ }^{40} \mathrm{o}$ Weyland. $\mathrm{Al}$ respecto, este último sostiene que los líderes populistas emergen si los partidos son rudimentarios o si los aspirantes populistas asumen el control de un partido populista existente, como fue el caso de Menem y el Partido Justicialista ${ }^{41}$.

${ }^{34}$ L. Paramio, «Giro a la izquierda...», op. cit., pp. 62-74.

35 K. WeYland, «Neopopulism and Neoliberalism in Latin America», Studies in Comparative International Development, vol. 31 (1996), pp. 3-31.

${ }^{36}$ L. PARAmIO, «La izquierda...», op. cit., pp. 26 y ss.

En relación con el Partido Justicialista durante la era menemista, véase el trabajo de S. Levitsky, Transforming Labor-Based Parties in Latin America: Argentine Peronism in Comparative Perspective, 1. ${ }^{a}$ ed., Cambridge, Cambridge University, 2003.

37 Se ha dicho que, desde un punto de vista económico, el populismo enfatiza el crecimiento a través de políticas distributivas en el corto plazo a fin de incrementar el consumo, descuidando los equilibrios macroeconómicos, en especial lo relativo a la inflación y el déficit fiscal. Sin embargo, en relación con los populismos de los años noventa, se afirma que si bien no hubo régimen económico populista clásico, hubo una suerte de microeconomía distributiva que se puede compatibilizar con una macroeconomía más o menos equilibrada. Cfr. A. Benavente Urbina y J. A. Cirinio, La democracia defraudada..., op. cit., p. 37.

${ }^{38}$ L. PARAmIO, «La izquierda...», op. cit., pp. 26 y ss.

39 J. LANZARO, «La "tercera ola" de las izquierdas latinoamericanas: entre el populismo y la socialdemocracia», Working Papers Online Series, México, UNAM, 2008.

${ }^{40}$ R. A. MAYORGA, «Antipolítica y neopopulismo en América Latina», Relaciones, núm. 161, Serie Convivencias (XV), Montevideo, Periódica SRL, 1997.

${ }^{41}$ K. Weyland, «Neoliberal populism...», op. cit., p. 385. 
De esta forma, en aquel contexto de crisis económica y crisis de representación surgió el gobierno de Menem, otorgándose una gran centralidad a su figura ${ }^{42}$. En esta línea, O'Donell ha llamado a estas democracias no como democracias representativas, sino como democracias «delegativas» ${ }^{43}$. Afirma que este tipo era estudiado como un capítulo del análisis de los autoritarismos, como el populismo, pero lo considera un tipo peculiar de democracia. Señala que las democracias delegativas se basan en la premisa de que quien sea que gane una elección presidencial tendrá el derecho a gobernar como él considere apropiado, restringido sólo por la realidad de las relaciones de poder existentes y por un periodo en funciones limitado constitucionalmente, considerándose al presidente como la encarnación del país, principal custodio e intérprete de sus intereses. Afirma que la rendición de cuentas ante el poder legislativo y el poder judicial aparecen como un mero obstáculo a la plena autoridad que le ha sido delegada al presidente. De esta forma se da una acentuada personalización y concentración en el poder ejecutivo, llevando al «decretismo». En la misma línea, Weyland señala que los líderes populistas hacen esfuerzos para concentrar el poder, realizando reformas a través de decreto ${ }^{44}$.

En este contexto, Menem ejerció en numerosas ocasiones funciones materialmente legislativas a través del dictado de los llamados decretos de necesidad y urgencia, y la delegación legislativa. Si bien aquellas potestades no estaban reconocidas constitucionalmente hasta ese entonces, la Corte Suprema convalidó este tipo de prácticas, adoptando criterios muy amplios para aceptar dicha reglamentación ${ }^{45}$.

${ }^{42}$ Si bien el presidente Menem fue considerado como el representante de una ruptura radical con el discurso democrático que había dominado el periodo de transición democrática bajo el gobierno de Alfonsín, centrado en la recuperación de las libertades y los derechos democráticos y en la institucionalización de un sistema de partidos democrático y estable, se ha sostenido que no hubo tal ruptura. Véase S. BARROS, «Las continuidades discursivas de la ruptura menemista», en F. PANIZZA (coord.), El populismo como espejo de la democracia, México, Fondo de Cultura Económica, 2009, pp. 351-381.

Por otro lado, cabe destacar que MANIN afirma que más que una crisis de representación se está experimentando una metamorfosis de la representación. Habla de tres formas de representación política: el parlamentarismo inglés clásico, la democracia de partidos y actualmente la democracia «de audiencias». Cfr. B. MAnIN, The Principles of Representative Government, Cambridge, Cambridge University Press, 1997.

${ }^{43}$ G. O’Donnell, «Delegative Democracy», Journal of Democracy, vol. 5, núm. 1 (1994), pp. 55-69.

${ }^{44}$ K. Weyland, «Neoliberal Populism...», op. cit., p. 391.

${ }^{45}$ En el caso de los decretos de necesidad y urgencia, la Corte Suprema argentina los convalidó en el precedente «Peralta» (CSJN, Peralta, Luis A. y otro c. Estado Nacional, Ministerio de Economía, BCRA, 27 de diciembre de 1990, Colección de Fallos de la Corte 
Por otro lado, O'Donell afirma que, en la medida en que las políticas sean reconocidas como exitosas por segmentos de la población que tienen peso electoral, los presidentes delegativos consideran simplemente odioso que sus periodos deban limitarse constitucionalmente ${ }^{46}$. En el caso bajo análisis cabe señalar que si bien se buscaba la continuidad del líder, la Constitución no preveía la reelección presidencial. Por tanto, y en atención a que el justicialismo no contaba con la mayoría necesaria para reformarla, se llegó a un acuerdo con la Unión Cívica Radical llamado el «Pacto de Olivos». Finalmente, la reforma constitucional se realizó en el año 1994, habilitándose la posibilidad de la reelección presidencial a la vez que se regularon los decretos de necesidad y urgencia, y la delegación legislativa, a fin de limitar dichas facultades, entre otras cuestiones.

De tal manera, el presidente Menem logró al año siguiente la reelección presidencial con el 49 por 100 de los votos. Sin embargo, a pesar de la regulación restrictiva respecto de los decretos antes mencionados ${ }^{47}$, el presidente Menem continuó utilizando aquellos mecanismos con mucha frecuencia ${ }^{48}$.

Pero a partir de 1997, como consecuencia de la crisis asiática de aquel año, las economías latinoamericanas dejaron de crecer. Asimismo, si bien la pobreza y la indigencia se habían reducido entre los años 1990 y 1997,

Suprema, t. 313, p. 1513). En lo que se refiere a la delegación legislativa, la Corte Suprema se alejó de los criterios acuñados históricamente para convalidar este tipo de normas, como que el poder ejecutivo puede «reglar los pormenores y detalles» (CSJN, A. M. Delfino y Cía., 20 de junio de 1927, Fallos 148:430) o que «la política legislativa haya sido claramente establecida» (CSJN, Prattico, Carmelo y otros c. Basso y Cía., 20 de mayo de 1960, Fallos 246:345), y aceptó aquel tipo de norma con un criterio más amplio, indicando que al menos debía respetar el «bloque de legalidad» (CSJN, Cocchia, Jorge D. c. Estado Nacional y otro, 2 de diciembre de 1993, Fallos 316:2624).

${ }^{46}$ G. O'DonnelL, «Delegative...», op. cit.

47 En efecto, el art. 99, inciso 3, de la Constitución argentina incorporado en la reforma constitucional de 1994 dispone que: «El poder ejecutivo no podrá en ningún caso, bajo pena de nulidad absoluta e insanable, emitir disposiciones de carácter legislativo. Solamente cuando circunstancias excepcionales hicieran imposible seguir los trámites ordinarios previstos por esta Constitución para la sanción de las leyes y no se trate de normas que regulen materia penal, tributaria, electoral o de régimen de los partidos políticos, podrá dictar decretos por razones de necesidad y urgencia». Respecto a la delegación legislativa, la excepcionalidad del instituto también surge del texto constitucional. El art. 76 de la Constitución dispone que «se prohíbe la delegación legislativa en el poder ejecutivo, salvo en materias determinadas de administración o de emergencia pública, con plazo fijado para su ejercicio y dentro de las bases de la delegación que el Congreso establezca».

${ }^{48}$ G. J. Bidart Campos y P. L. Manili, «La jerarquía normativa de las distintas clases de decretos del poder ejecutivo. A propósito de la moderna "decretocracia" argentina», $L a$ Ley, t. 2003-C, p. 1359. 
ambos indicadores comenzaron a crecer y se vieron frustradas las altas expectativas que los propios gobiernos habían creado sobre la entrada de un crecimiento estable y duradero ${ }^{49}$.

El presidente Menem finalizó su mandato en el año 1999. En aquella fecha asumió la presidencia Fernando De la Rúa, quien debió abandonar el gobierno dos años más tarde en una de las peores crisis de la historia Argentina, lo que dio lugar a que los ciudadanos se manifestaran en las calles bajo el lema «que se vayan todos», situación demostrativa de la crisis de representación que estaba teniendo lugar en el país.

La crisis de representación fue un excelente caldo de cultivo para el nacimiento de un gobierno con notas populistas. Tras la salida de De la Rúa se sucedieron en pocos días varios presidentes ${ }^{50}$, recayendo la presidencia finalmente en Eduardo Duhalde, quien había perdido la elección en 1999 y quien gobernó hasta el año 2003.

En las elecciones de ese año la presidencia quedó en manos de Néstor Kirchner. Si bien éste había obtenido un 22 por 100 de los votos frente al 24 por 100 logrado por Menem, este último renunció a celebrar la segunda vuelta, por lo que Kirchner se convirtió en presidente con el voto favorable de menos de una cuarta parte del electorado.

Años antes había llegado al poder en Venezuela Hugo Chávez, quien, como se ha dicho, hizo recordar que la tradición populista no había muerto en América Latina. Su discurso reprodujo muchos elementos de la retórica populista tradicional como, por ejemplo, la exaltación de la autenticidad popular y de las virtudes nacionales, la crítica de la política representativa y a sus profesionales, y la sublimación del vínculo directo entre el líder y su pueblo ${ }^{51}$. De esta forma se afirma que al comienzo del nuevo siglo el populismo ha regresado a su forma tradicional de populismo redistribuidor, y se dio también en un contexto de crisis de representación. Se ha dicho que el discurso populista de Chávez se manifestó en que en su retórica se encontraba el rechazo a los partidos como cómplices de la oligarquía y traidores a los intereses populares. También llevó a cabo un proceso de reconstrucción de las instituciones políticas para eli-

49 L. Paramio, «La izquierda...», op. cit., pp. 26 y ss.

50 Tras la salida de De la Rua el 21 de diciembre de 2001 y la llegada de Eduardo Duhalde el 2 de enero se sucedieron en la presidencia Ramón Puerta, Adolfo Rodríguez Saa y Eduardo Camaño.

51 G. Hermet, S. Loaeza y J.-F. Prud'Homme (coords.), Del populismo de los antiguos al populismo de los modernos, 1. a ed., México, El Colegio de México-Centro de Estudios Internacionales, 2001, p. 9. 
minar cualquier obstáculo al nuevo régimen «bolivariano». Sin embargo, más allá de la forma de gobernar del presidente venezolano, es indiscutible que sus nuevas reglas de juego cumplen formalmente los criterios democráticos ${ }^{52}$.

Tanto Chávez como Kirchner llegan al gobierno con una clara conciencia de que las políticas neoliberales habían fracasado para la población. En cuanto al caso argentino, Kirchner optó por un Estado activista e intervencionista en un contexto de ascenso de los precios de las materias primas y de los alimentos, lo cual amplió de forma sustancial los ingresos fiscales del país. Al disminuir las restricciones fiscales, el gobierno pudo ampliar el gasto social y las inversiones públicas, y, por tanto, existía el contexto propicio para un renacido protagonismo del Estado ${ }^{53}$.

El gobierno de Kirchner fue con el tiempo ganando mayor apoyo popular. Así, en las elecciones presidenciales de 2007 fue proclamada presidenta la esposa del entonces jefe de Estado, Cristina Fernández, con el 46 por 100 de los votos. La popularidad de la jefa de Estado fue incrementándose cada vez más, siendo reelegida en las elecciones presidenciales del año 2011 con el 54 por 100 de los votos.

$\mathrm{Si}$ bien Lanzaro tampoco considera al gobierno kirchnerista como populista, sino como un gobierno que proviene de un partido de raigambre nacional-popular existente con anterioridad a su recreación del peronismo en Argentina, afirma que el gobierno de Kirchner parece reincidir en vicios típicos de la política argentina y de la propia saga peronista, que derivan básicamente de las fallas seculares del sistema de partidos y, en particular, de su recurrente asimetría. Destaca que el déficit histórico de pluralismo y la falta de contrapesos, el centralismo y la cultura decisionista, los obrajes mayoritarios y la ausencia de una oposición partidaria contundente que haga desempeñar los equilibrios políticos y organice el balance institucional, ha habilitado una acumulación de recursos económicos y jurídicos —-incluyendo la delegación de facultades legislativas y los decretos de necesidad y urgencia— que hicieron de Kirchner un líder muy poderoso ${ }^{54}$.

52 L. Paramio, «Giro a la izquierda...», op. cit.

53 L. Paramio, «El regreso del Estado: entre el populismo y la regulación», Revista del CLAD: reforma y democracia, vol. 42 (2008), p. 19.

Sobre la política de los servicios públicos en los gobiernos kirchneristas véase A. R. TimPANARO, «Reflexiones sobre la política actual de servicios públicos a propósito de la expropiación de Aerolíneas Argentinas y Austral», La Ley, suplemento administrativo (2014), p. 18.

54 J. LANZARO, «La “tercera ola”...», op. cit. 
Sobre el particular cabe apuntar que con motivo de la crisis económica de finales de 2001 se dictó la Ley $25.561^{55}$, que declaró la emergencia pública en materia social, económica, administrativa, financiera y cambiaria, delegando al poder ejecutivo nacional determinadas facultades extraordinarias por un término aproximado de dos años. Sin embargo, a través de sucesivas prórrogas su vigencia llegará hasta el mes de diciembre de $2015^{56}$, por lo que una norma que delega amplios poderes al poder ejecutivo estará vigente durante catorce años.

Por otro lado, Elórtegui Gómez, en un reciente libro sobre la forma de comunicación en los populismos, destaca que los anclajes narrativos del kirchnerismo se sitúan en la democracia y justicia del peronismo de los ochenta, el compromiso político de los setenta, el rol del Estado nacional o peronismo del desarrollo, y los ideales de equidad, trabajo y consolidación de la industria. Afirma que, en definitiva, la historia es la que se pone en disputa y conflicto, por ello Cristina Fernández orienta su discurso contra los atropellos a los derechos humanos cometidos en la dictadura y la lucha frente a Gran Bretaña por las Islas Malvinas, entre otros ${ }^{57}$. En este contexto, destaca que el kirchnerismo ha creado un antagonismo con las corporaciones, sean militares, empresas extranjeras, organismos multilaterales de crédito o empresas periodísticas. Asimismo, otra de las cuestiones fundamentales del relato desde que la muerte arrebató a Néstor Kirchner de la escena política Argentina la constituye el hecho de que Cristina Fernández recuerda su legado y su presencia en los actos y mensajes de trascendencia, envolviendo esos momentos con una emocionalidad que conmueve, produce empatía, lágrimas y adhesiones ${ }^{58}$.

En particular, cabe resaltar que se ha creado un antagonismo con otro de los poderes del Estado, el poder judicial ${ }^{59}$. En efecto, en el año 2013 el

55 Boletín Oficial de la República Argentina, 7 de enero de 2002.

${ }^{56}$ En efecto, la Ley 25.561 fue prorrogada por las Leyes 25.972 (BO, 17 de diciembre de 2004), 26.077 (BO, 10 de enero de 2006), 26.204 (BO, 20 de diciembre de 2006), 26.339 (BO, 4 de enero de 2008), 26.456 (BO, 16 de diciembre de 2008), 26.563 (BO, 22 de diciembre de 2009), 26.729 (BO, 28 de diciembre de 2011) y, por último, por la Ley 26.896 (BO, 22 de octubre de 2013). Véase al respecto J. S. YlarRI, «La emergencia sin fin», El Cronista Comercial, diario del 30 de septiembre de 2013, p. 14.

57 En este contexto cabe señalar que por medio del Decreto 833/14 (BO, 4 de junio de 2014) se creó la Secretaría de Coordinación Estratégica para el Pensamiento Nacional en el ámbito del Ministerio de Cultura de la Nación.

58 C. Elórtegui Gómez, Populismo..., op. cit., pp. 273-274. Asimismo, cabe referir que con el fallecimiento de Néstor Kirchner en 2010, a lo largo de todo el país se han renombrado calles, plazas, edificios, con el nombre del expresidente ( $\mathrm{El}$ nombre Kirchner y el culto a la personalidad», La Nación, diario del 15 de octubre de 2014).

${ }_{59}$ A modo de ejemplo cabe señalar que en un reciente acto para celebrar los treinta y un 
poder ejecutivo presentó seis proyectos de ley tendentes a «democratizar la justica» que finalmente fueron aprobados ${ }^{60}$. Sin embargo, la Corte Suprema resolvió declarar la inconstitucionalidad de la Ley 26.855 en cuanto modificaba la composición del Consejo de la Magistratura y la forma de elección de algunos de sus integrantes, por ser contraria al art. 114 de la Constitución ${ }^{61}$. $\mathrm{Al}$ respecto, el máximo tribunal, recordando un precedente anterior ${ }^{62}$, señaló que «la doctrina de la omnipotencia legislativa que se pretende fundar en una presunta voluntad de la mayoría del pueblo es insostenible dentro de un sistema de gobierno cuya esencia es la limitación de los poderes de los distintos órganos y la supremacía de la Constitución» ${ }^{63}$. En este contexto se presentan como sumamente actuales las palabras de Hamilton en El Federalista cuando señalaba que «la Constitución es de hecho una ley fundamental y así debe ser considerada por los jueces», por lo que no era legítimo que los representantes del pueblo violaran «las previsiones de la Constitución vigente cada vez que una afición pasajera dominara a una mayoría de sus electores en un sentido contrario a dichas disposiciones».

Asimismo, otro aspecto que se ha dado en esta etapa es la falta de control por parte del poder legislativo al poder ejecutivo, pudiendo citarse como ejemplo la falta de control por parte del Congreso de la cuenta de inversión ${ }^{64}$.

años de la recuperación de la democracia y el Día Internacional de los Derechos Humanos, Cristina Fernández criticó a los «sicarios mediáticos» y a sus «secuaces judiciales» («Cristina criticó a la Justicia y defendió a los funcionarios investigados», La Nación, diario del 14 de diciembre de 2014).

${ }^{60}$ Fueron dictadas las Leyes 26.853 (BO, 17 de mayo de 2013), que crea la Cámara Federal de Casación en lo Contencioso-Administrativo Federal, la Cámara Federal y Nacional de Casación del Trabajo y la Seguridad Social, y la Cámara Federal y Nacional de Casación en lo Civil y Comercial; 26.854 (BO, 30 de abril de 2013), que regula las pretensiones cautelares postuladas contra toda actuación u omisión del Estado nacional o sus entes descentralizados o solicitadas por éstos; 26.855 (BO, 27 de mayo de 2013), que modifica la composición del Consejo de la Magistratura; 26.856 (BO, 23 de mayo de 2013), que establece que la Corte Suprema de Justicia de la Nación y los tribunales de segunda instancia que integran el poder judicial de la Nación deberán publicar íntegramente todas las acordadas y resoluciones que dicten el mismo día de su dictado; 26.857 ( $B O, 23$ de mayo de 2013), sobre ética en el ejercicio de la función pública, y 26.861 (BO, 3 de junio de 2013), que regula el «el ingreso democrático e igualitario de personal al poder judicial de la Nación y al Ministerio Público de la Nación mediante el procedimiento de concurso público» (art. 1. $\left.{ }^{\circ}\right)$.

${ }^{61} \mathrm{Al}$ respecto véase J. S. YLARRI, «El equilibrio en la composición del Consejo de la Magistratura», Debates de Actualidad, núm. 207 (2013), pp. 79-93.

${ }_{62}$ CSJN, Horta, Jose c/ Harguindeguy, Ernesto, 21 de agosto de 1922, Fallos 137:47.

${ }_{63}$ CSJN, Rizzo, 18 de julio de 2013, expediente R.369.XLIX.

${ }^{64} \mathrm{~J}$. S. YLARRI, «La cuenta de inversión: el control por parte del Congreso de la Nación», La Ley, Suplemento Actualidad, 13 de septiembre de 2012, pp. 1-3. 
Finalmente, cabe señalar que se ha pasado así de una situación de crisis de representación con el lema «que se vayan todos» al planteamiento de la consigna «vamos por todo» ${ }^{65}$. Así, se ha llegado a pensar en una reforma constitucional para habilitar una reelección presidencial indefini$\mathrm{da}$, aunque finalmente no se ha llevado a cabo ${ }^{66}$. Cristina Fernández finaliza su mandato en diciembre de 2015. Habrá que analizar en los próximos años las consecuencias jurídicas, políticas y sociales que se deriven del proceder aquí descrito.

4. En el presente trabajo se han procurado analizar las principales características del populismo y se ha analizado si este fenómeno se ha dado en Argentina. Se ha hecho una breve referencia al populismo histórico de Perón, al gobierno neoliberal de la última década del siglo xx y al gobierno de tipo redistributivo que se ha dado a comienzos de siglo.

Los populismos han surgido precisamente por crisis de representación. En el nuevo populismo de principios de siglo esa crisis se vio plasmada en el descreimiento a los partidos políticos y el reclamo de «que se vayan todos».

Como se ha visto, la política económica no es un parámetro para encasillar a un gobierno como populista; lo cierto es que en Argentina se han dado gobiernos con notas de populismo con políticas neoliberales y con un Estado abstencionista, como el menemismo, y un gobierno con notas populistas con políticas distributivas y con gran presencia estatal.

En este contexto cabe destacar que luego de aquellas crisis de representación en las que gran parte de la sociedad sentía que ninguno de los partidos políticos representaba sus intereses - las cuales antecedieron los gobiernos menemista y kirchnerista—, ambos gobiernos se distinguieron por la fuerte presencia de un líder carismático. El discurso populista, especialmente en los gobiernos kirchneristas, como en todo populismo, se ha centrado en asumir la representación del pueblo del líder y descalificar a la oligarquía, llegando a incluir en este grupo al poder judicial. Asimismo, este fuerte liderazgo ha llevado a opacar la función de otro de los poderes del Estado y una deficiente rendición de cuentas.

A su vez, otra de las características ha sido la vocación de la continuidad de los líderes. El presidente Menem logró la reforma constitucional

${ }^{65}$ «Se cumple un año del "vamos por todo" de la Presidenta», La Nación, diario del 27 de febrero de 2013.

${ }^{66}$ En este sentido, se ha hablado públicamente de tener una «Cristina eterna». La frase fue pronunciada por la diputada Diana Conti el 28 de febrero de 2011 ( «Los ultra K ya hablan de "Cristina eterna" y reelección indefinida», Clarín, diario del 1 de marzo de 2011, y «Pienso en el proyecto eterno», Página 12, diario del 5 de enero de 2013). 
y la reelección. Por su parte, los gobiernos de Néstor Kirchner y Cristina Fernández han alcanzan los tres periodos, aunque no han logrado imponer una nueva reforma a fin de obtener una reelección indefinida.

Finalmente, cabe poner de relieve los graves riesgos que comportan los populismos para la democracia, en tanto generan desconfianza de los ciudadanos en las instituciones. Debe tenerse en cuenta que aquella polarización política se traduce luego en polarización social. Resulta necesario, por el contrario, fortalecer las instituciones, lograr que los gobiernos sean «de leyes y no de hombres» ${ }^{67}$. En definitiva, fortalecer el sistema de partidos en tanto ellos son - como los describe el art. 38 de la Constitución argentina- «instituciones fundamentales del sistema democrático».

\section{BIBLIOGRAFÍA}

ARDiTI, B., «El populismo como periferia interna de la política democrática», en F. PANizza (coord.), El populismo como espejo de la democracia, México, Fondo de Cultura Económica, 2009, pp. 97-132.

Arranz, R. M., «El liderazgo carismático en el contexto del estudio del liderazgo», en J. Álvarez Junco (coord.), Populismo, caudillaje y discurso demagógico, 1. a ed., Madrid, Centro de Investigaciones Sociológicas, 1987, pp. 73-99.

AtienZA, M., El derecho como argumentación, Barcelona, Ariel, 2006.

BARROS, S., «Las continuidades discursivas de la ruptura menemista», en F. PANIZZA (coord.), El populismo como espejo de la democracia, México, Fondo de Cultura Económica, 2009, pp. 351-381.

Benavente Urbina, A., y Cirinio, J. A., La democracia defraudada. Populismo revolucionario en América Latina, 1. ${ }^{a}$ ed., Buenos Aires, Grito Sagrado, 2005.

Bidart Campos, G. J., y Manili, P. L., «La jerarquía normativa de las distintas clases de decretos del poder ejecutivo. A propósito de la moderna "decretocracia” argentina», La Ley, t. 2003-C, p. 1359.

Dornbusch, R., y Edwards, E. (eds.), The Macroeconomics of Populism in Latin America, Chicago, University of Chicago Press, 1991.

Elórtegui Gómez, C., Populismo y comunicación: la política del malestar en el contexto latinoamericano, 1. ${ }^{\text {a }}$ ed., Barcelona, UOC, 2013.

FerREYRA, L. E., «Control legislativo de los decretos delegados y de necesidad y urgencia», Revista Jurídica Argentina La Ley, diario del 7 de septiembre de 2012, p 1.

GuTIÉRREZ, I. (coord.), La democracia indignada. Tensiones entre voluntad popular y representación política, Granada, Comares, 2014.

${ }^{67}$ Suprema Corte de Estados Unidos, Marbury v. Madison, 1803, 5 U.S. (1 Cranch) 137. 
Hermet, G.; Loaeza, S., y Prud'Homme, J. F. (coords.), Del populismo de los antiguos al populismo de los modernos, 1. . ed., México, El Colegio de México-Centro de Estudios Internacionales, 2001.

Laclau, E., La razón populista, México, Fondo de Cultura Económica, 2005.

- «Populismo: ¿qué nos dice el nombre?», en F. Panizza (coord.), El populismo como espejo de la democracia, México, Fondo de Cultura Económica, 2009, pp. 51-70.

LANZARO, J., «La "tercera ola” de las izquierdas latinoamericanas: entre el populismo y la social-democracia», Working Papers Online Series, México, UNAM, 2008.

- (ed.), Presidencialismo y parlamentarismo. América Latina y Europa meridional, Madrid, Centro de Estudios Políticos y Constitucionales, 2012.

LeVITsky, S., Transforming Labor-Based Parties in Latin America: Argentine Peronism in Comparative Perspective, 1. ${ }^{a}$ ed., Cambridge, Cambridge University, 2003.

Manin, B., The Principles of Representative Government, Cambridge, Cambridge University Press, 1997.

Mayorga, R. A., «Antipolítica y neopopulismo en América Latina», Relaciones, núm. 161, Serie Convivencias (XV), Montevideo, Periódica SRL, 1997.

Moscoso Perea, C., El populismo en América Latina, Madrid, Centro de Estudios Constitucionales, 1990.

O’Donnell, G., «Delegative Democracy», Journal of Democracy, vol. 5, núm. 1 (1994), pp. 55-69.

PanizzA, F., «El populismo como espejo de la democracia», en F. PANIzZA (coord.), El populismo como espejo de la democracia, México, Fondo de Cultura Económica, 2009, pp. 9-49.

PARAmIO, L., «Cambios sociales y desconfianza política: el problema de la agregación de preferencias», Revista Española de Ciencia Política, núm. 1 (1999), pp. 81-95.

- «Crisis de gobernabilidad y populismo», en L. Paramio y M. Revilla (coords.), Una nueva agenda de reformas políticas en América Latina, Madrid, Fundación Carolina, 2006, p. 17.

- «El regreso del Estado: entre el populismo y la regulación», Revista del CLAD. Reforma y democracia, vol. 42 (2008), p. 19.

— «Giro a la izquierda y regreso del populismo», Nueva Sociedad, vol. 205 (2006), pp. 62-74.

- «La izquierda y el populismo», en P. Pérez Herrero (coord.), La «izquierda» en América Latina, Madrid, Pablo Iglesias, 2006, p. 26.

Pitkin, H., The Concept of Representation, Berkeley, University of California Press, 1967.

SCHEDLER, A., Electoral authoritarianism, Boulder, Lynne Rienner, 2006.

SEn, A., La idea de la justicia, Buenos Aires, Taurus, 2009.

Timpanaro, A. R., «Reflexiones sobre la política actual de servicios públicos a propósito de la expropiación de Aerolíneas Argentinas y Austral», La Ley, suplemento administrativo (2014), p. 18. 
TORRes Ballesteros, S., «El populismo. Un concepto escurridizo», en J. Álvarez Junco (comp.), Populismo, caudillaje y discurso demagógico, 1. ${ }^{a}$ ed., Madrid, Centro de Investigaciones Sociológicas, 1987, pp. 159-180.

Weyland, K., «Neoliberal populism in Latin America and Eastern Europe», Comparative Politics, vol. 31, núm. 4 (1999), pp. 379-401.

- «Neopopulism and neoliberalism in Latin America», Studies in Comparative International Development, vol. 31 (1996), pp. 3-31.

Ylarri, J. S., «El equilibrio en la composición del Consejo de la Magistratura», Debates de Actualidad, núm. 207 (2013), pp. 79-93.

— «La cuenta de inversión: el control por parte del Congreso de la Nación», La Ley, Suplemento Actualidad, 13 de septiembre de 2012, pp. 1-3.

- «La emergencia sin fin», El Cronista Comercial, diario del 30 de septiembre de 2013, p. 14. 
